\title{
IS TOOTH ENAMEL CARBONATE A SUITABLE MATERIAL FOR RADIOCARBON DATING?
}

\author{
R. E. M. HEDGES, ${ }^{1}$ J. A. LEE-THORP ${ }^{2}$ and N. C. TUROSS ${ }^{3}$
}

\begin{abstract}
We present the results of 18 radiocarbon determinations on the carbonate fraction of tooth enamel prepared from nine separate teeth. The known ages of the teeth vary from 11 to $>200 \mathrm{ka} \mathrm{BP}$, and are from three sites. The sample preparation procedures varied somewhat, but were broadly based on procedures found to give satisfactory results on carbon stable Thise measurements. All the ${ }^{14} \mathrm{C}$ dates obtained are too young, by an equivalent contamination of ca. $6 \%$ Modern (pMC). This value is fairly consistent despite variations in sample preparation. We discuss the implications for using enamel as a possible alternative to bone when insufficient collagen is available.
\end{abstract}

\section{INTRODUCTION}

We report here work aimed at evaluating the potential of tooth enamel carbonate for radiocarbon dating. The motivation and rationale for doing this are as follows: 1) carbonate can be recovered from tooth enamel in depositional contexts in which bone collagen does not survive, so that its ${ }^{14} \mathrm{C}$ measurement could permit the direct dating of otherwise undatable (by ${ }^{14} \mathrm{C}$ ) faunal remains; 2) a substantial history exists of ${ }^{14} \mathrm{C}$ dating carbonate from bone apatite, which gives some encouragement. This is greatly strengthened by more recent work on stable carbon isotope $\left(\delta^{13} \mathrm{C}\right)$ measurements on the carbonate fraction of tooth enamel, which we discuss more fully below. Also, studies of diagenetic changes in bone are beginning to elucidate the chemistry by which carbonate ions are exchanged or incorporated, and to improve methods for their removal.

Enamel differs from bone and dentine in possessing a greatly reduced organic molecular content $(<2 \%)$, a much lower porosity and surface area, and a greater degree of crystallinity. Biological apatites resemble the mineral dahllite, with substitutions in the $\mathrm{PO}_{4}$ and $\mathrm{Ca}$ positions. Carbonate ions are both substituted in the former position and are also adsorbed on surfaces and at hydration layers (Legeros et al. 1969; Brown and Chow 1976; Rey et al. 1991). This structure is diagenetically more stable in enamel than in bone. Enamel typically contains $0.5-1 \%$ by weight of carbon as carbonate. Collecting enamel samples in quantities of up to $100 \mathrm{mg}$ is feasible, and ${ }^{14} \mathrm{C}$ dating is only possible using accelerator mass spectrometry (AMS). The pretreatment methods necessary to prevent diagenetically altered carbonate from being measured can be based on previous work developed for stable isotope measurements. The two types of isotopic measurements, $\delta^{14} \mathrm{C}$ and $\delta^{13} \mathrm{C}$, are, of course, sensitive in different ways to alteration of the original carbon isotope composition by incorporation of exogenous carbonate.

\section{Previous Research}

\section{Radiocarbon Dating}

Bone contains a few percent of carbon as carbonate, and this has been used for ${ }^{14} \mathrm{C}$ dating, although the reliability of the method has not been generally accepted, despite long-term efforts (Tamers and Pearson 1965; Haynes 1968; Hassan, Termine and Haynes 1977; Sullivan and Krueger 1981; Saliege, Person and Paris 1995). Some chemical treatment to remove exogenous carbonate is necessary-usually limited acid hydrolysis is used. Another approach uses $\mathrm{CO}_{2}$ fractions differentially

\footnotetext{
${ }^{1}$ Radiocarbon Accelerator Unit, Research Laboratory for Archaeology and the History of Art, Oxford University,

6 Keble Road, Oxford OX1 3QJ England

${ }^{2}$ Department of Archaeology, University of Cape Town, Rondebosch 7700 South Africa

${ }^{3}$ Conservation Analytical Laboratory, Museum Support Center, Smithsonian Institution, Washington, DC 20560 USA
} 
liberated over an increasing temperature range, the least exchangeable carbonate fraction being released last (Haas and Banewicz 1980). Obtaining a ${ }^{14} \mathrm{C}$ age in agreement with the expected age is not always a sufficient criterion that exogenous carbon has been removed, however, because it may have a similar ${ }^{14} \mathrm{C}$ age. This is not unlikely for material in the age range of 2 to $8 \mathrm{ka} \mathrm{BP}$, but is generally much less likely for material $>20 \mathrm{ka}$ BP. To our knowledge, no previous AMS measurements have been made on tooth enamel carbonate; a comparison of a bone carbonate date with other (amino acid) fractions is given in Stafford et al. (1991).

\section{Dietary Studies}

The $\delta^{13} \mathrm{C}$ value of bone and enamel carbonate contains different information from that of collagen carbon. Further, such biological information is potentially available from Lower Pleistocene material, because carbonate is still present. Thus, the field is being actively researched (see Lee-Thorp and van der Merwe (1991) for further references). For ${ }^{13} \mathrm{C}$, the difference in isotopic composition between endogenous and exogenous material is seldom $>10 \%$, and a $10 \%$ mixing of exogenous material should be just detectable in favorable cases. Studies on archaeological faunal material (LeeThorp and van der Merwe 1991; Bocherens et al. 1995) suggest that if the enamel is carefully pretreated, the original isotopic composition is sufficiently preserved for the recovery of the original composition. This is in contrast to work on bone, for which scientists still disagree on the ability to recover original signals (Sullivan and Krueger 1981, 1983; Schoeninger and DeNiro 1983; LeeThorp and van der Merwe 1987; Koch et al. 1995).

\section{Diagenesis and Pretreatment}

Both carbonate exchange and the additional adsorption and/or deposition of carbonate ions are expected to occur. One frequently observes deposition of carbonate as calcite, which decomposes faster than dahllite-type apatites when exposed to weak acids. Carbonate exchange is a more serious problem. Krueger recently conducted an interesting experiment (1991), in which he showed that "properly cleaned" bone apatite did not retain significant quantities of exchanged carbonate when immersed for $2 \mathrm{yr}$ in 10 atom $\%{ }^{13} \mathrm{C}$ carbonate, or for $11 \mathrm{ka}$ in seawater of $10 \%$ difference in $\delta^{13} \mathrm{C}$. Proper cleaning, in this case, meant periodic evacuation in $1 \mathrm{~N}$ acetic acid for $48 \mathrm{hr}$. Some controversy has been generated by the effects of different pretreatment methods (Lee-Thorp and van der Merwe 1991) since inappropriate methods may cause artifacts. Acetic acid treatment may induce isotopic exchange of carbonate oxygen (Koch et al. 1995), while prolonged immersion in strong acetic acid has been shown to stimulate the formation of brushite $\left(\mathrm{HCaPO}_{4} \cdot 2 \mathrm{H}_{2} \mathrm{O}\right)($ Lee-Thorp and van der Merwe 1991). Most workers now recommend a bleaching treatment to remove organic carbon followed by treatment with $1 \mathrm{~N}$ or $0.1 \mathrm{~N}$ acetic acid.

However, the success of any particular pretreatment method at this stage tells us relatively little about the diagenetic processes responsible for incorporating exogenous carbonate. There is little direct evidence for the rather vague models of diagenetic alteration, and such basic questions as what proportion of structural carbonate is potentially exhangeable have no answer at present. The issue has important implications, not only for the studies referred to here, but for example, for any potential extension to the ${ }^{14} \mathrm{C}$ dating of carbonate in bone, where even a small degree of diagenetic alteration may be more serious.

\section{THIS STUDY}

\section{Material}

We selected material from three sites; two calcitic cave systems (Kent's Cavern in England and Equus Cave, South Africa) and a generally anoxic, silty, fluvial deposit on limestone (Stanton Har- 
court, England). These sites yielded convenient megafauna, were suitably old (in order to maximize the sensitivity to modern contamination) and are the subject of related studies (e.g., electron spin resonance (ESR) dating of enamels at Stanton Harcourt, diagenetic studies at Kent's Cavern, dating and stable isotope studies at Equus Cave). Details concerning the material are in Table 1.

\section{Pretreatment}

Pretreatment varied slightly depending on the site. Samples from Stanton Harcourt were prepared at the Radiocarbon Accelerator Unit, Oxford, Kent's Cavern at the Conservation and Analytical Laboratory of the Smithsonian Institution, and Equus Cave at the Department of Archaeology at Capetown, the latter two by methods developed for stable isotope studies. All three laboratories confirmed through AMS measurement that their acetic acid (HAc) contained no ${ }^{14} \mathrm{C}$, and that $\mathrm{CO}_{2}$ liberated from geological (Tertiary) calcite was at least $50 \mathrm{ka}$ BP.

\section{Stanton Harcourt}

The expected age of the large number of mammoths found at this site was from 200-250 ka, so the enamel should have contained no detectable ${ }^{14} \mathrm{C}$. We made two independent consecutive preparations. Enamel was extracted by hand and broken into $1-\mathrm{mm}$ fragments. These were treated with dil $(0.5 \mathrm{M}) \mathrm{HCl}$ for $20 \mathrm{sec}$, followed by $1 \mathrm{~N} \mathrm{NaOH}(20 \mathrm{sec})$, then washed and crushed to $\mathrm{ca}$. $50-100 \mu$. The fine powder was treated with $10 \% \mathrm{H}_{2} \mathrm{O}_{2}$ overnight, followed by $1 \mathrm{M} \mathrm{HAc}$ in a vacuum system, which allowed us to collect any evolved $\mathrm{CO}_{2}$ for $2 \mathrm{hr}$. In fact, we were unable to collect enough $\mathrm{CO}_{2}$ for subsequent measurement. After removal of the HAc, followed by washing in acidifed water, the evolution of $\mathrm{CO}_{2}$ from the enamel by the action of phosphoric acid was collected in two stages, on the assumption that the earlier stage was likely to contain more diagenetically altered material. (The results do not bear out this assumption.)

\section{Kent's Cavern}

We selected teeth from herbivores and carnivores and used them to provide control dates from dentine. Enamel was ground to $0.5 \mathrm{~mm}$, bleached in $2 \%$ "Clorox" overnight, rinsed 5 times with water, then treated either with $1 \mathrm{~N}$ acetic acid or $1 \mathrm{~N} \mathrm{HCl}$; the $\mathrm{HAc}$ treatment being overnight, the $\mathrm{HCl}$ for $5 \mathrm{~min} ; \mathrm{CO}_{2}$ is collected from phosophoric acid treatment. The ages found for the collagen fraction agreed with archaeological expectation, with the possible exception of OxA-4831, which is somewhat younger (Table 1). The date on the breccia is from the carbonate fraction, and indicates the likely ${ }^{14} \mathrm{C}$ age of the main source of exchangeable carbonate ions.

\section{Equus Cave}

Enamel from two samples was prepared by overnight bleaching with $2 \% \mathrm{NaOCl}$, followed by several days in $1 \mathrm{~N} \mathrm{HAc}$, before the $\mathrm{CO}_{2}$ liberated by $\mathrm{H}_{3} \mathrm{PO}_{4}$ was collected. Equus Cave ${ }^{4}$ is not well dated, and the age of each sample is not exactly known.

\section{RESULTS}

We present our findings (as ${ }^{14} \mathrm{C}$ dates) in Table 1 . We include a column in which we have calculated the percent of equivalent modern carbon required as contaminant to reconcile the enamel carbonate date with the expected date.

\footnotetext{
${ }^{4} \mathrm{P} 5264$ is from Square 20I, depth 52-60 cm and underlay a bone dated (from collagen) to $7840 \pm 80 \mathrm{BP}$ (Pta-2495), and overlay an ostrich eggshell dated to $11870 \pm 105 \mathrm{BP}$ (AA-5826). P5265 is from Square $24 \mathrm{~J}$, depth $180-187 \mathrm{~cm}$. It is above, but in the same general stratum as an ostrich eggshell dated to 27,330 $\pm 340 \mathrm{BP}$ (AA-5827).
} 
TABLE 1. Results of ${ }^{14} \mathrm{C}$ Dating Tooth Enamel Carbonate

\begin{tabular}{|c|c|c|c|c|c|c|c|c|c|c|}
\hline $\begin{array}{l}\text { ORAU } \\
\text { ID }\end{array}$ & Site & $\begin{array}{l}\text { Sample } \\
\text { ID }\end{array}$ & Species & Prep* & $\begin{array}{c}\text { OxA- } \\
\text { no. }\end{array}$ & Date & Error & $\begin{array}{c}\% \\
{ }^{14} \mathrm{C}\end{array}$ & $\begin{array}{l}\text { Exp. } \\
\% \text { C } \dagger\end{array}$ & $\begin{array}{c}\text { Differ- } \\
\text { ence }\end{array}$ \\
\hline \multirow[t]{4}{*}{ P5939 } & \multirow[t]{4}{*}{ Stanton Harcourt } & & Mammoth & HAc-HP1 & 5097 & 19,560 & 340 & 8.98 & 0 & 8.98 \\
\hline & & & Mammoth & HAc-HP1 & 5098 & 22,780 & 380 & 6.08 & 0 & 6.08 \\
\hline & & & Mammoth & HAc-HP2 & 5099 & 18,100 & 260 & 10.74 & 0 & 10.74 \\
\hline & & & Mammoth & HAc-HP2 & 5100 & 19,560 & 260 & 8.98 & 0 & 8.98 \\
\hline P4097 & Kent's Cavern & 25 & Rhino & Colla & 3403 & 39,630 & 1420 & 0.72 & $0.5-1$ & \\
\hline \multirow[t]{4}{*}{ P4099 } & & 25.1 & Rhino & HP & 4271 & 16,250 & 200 & 13.23 & $0.5-1$ & 12.51 \\
\hline & & 25.5 & Rhino & HP & 4275 & 18,540 & 200 & 9.95 & $0.5-1$ & 9.23 \\
\hline & & 25.3 & Rhino & $\mathrm{HCl}-\mathrm{HP}$ & 4273 & 24,570 & 310 & 4.70 & $0.5-1$ & 3.97 \\
\hline & & 25.4 & Rhino & HAc-HP & 4274 & 19,760 & 200 & 8.54 & $0.5-1$ & 7.82 \\
\hline P6064 & \multirow[t]{3}{*}{ Kent's Cavern } & $4 / 3470$ & Rhino & Colla & 4829 & 40,600 & 1700 & 0.64 & $0.5-1$ & \\
\hline P6058 & & $4 / 3470$ & Rhino & $\mathrm{HCl}-\mathrm{HP}$ & 4823 & 17,530 & 140 & 11.28 & $0.5-1$ & 10.64 \\
\hline P6056 & & $4 / 3470$ & Rhino & HAc-HP & 4821 & 25,400 & 280 & 4.23 & $0.5-1$ & 3.60 \\
\hline P6065 & \multirow[t]{2}{*}{ Kent's Cavern } & $9 / 5315$ & Hyena & Colla & 4830 & 39,400 & 1500 & 0.74 & $0.5-1$ & \\
\hline P6061 & & $9 / 5315$ & Hyena & $\mathrm{HCl}-\mathrm{HP}$ & 4826 & 8390 & 120 & 35.19 & $0.5-1$ & 34.50 \\
\hline P6066 & \multirow[t]{3}{*}{ Kent's Cavern } & $2 / 3536$ & Horse & Colla & 4831 & 27,640 & 400 & 3.20 & $0.5-1$ & \\
\hline $\mathrm{P} 6062$ & & $2 / 3536$ & Horse & HCl-HP & 4827 & 10,920 & 100 & 25.68 & $0.5-1$ & 22.40 \\
\hline P6059 & & $2 / 3536$ & Horse & HAc-HP & 4824 & 21,040 & 240 & 7.29 & $0.5-1$ & 4.04 \\
\hline P6057 & Kent's Cavern & $9 / 3478$ & Horse & $\mathrm{HCl}-\mathrm{HP}$ & 4822 & 14,810 & 130 & 15.82 & $0.5-1$ & 15.00 \\
\hline P6063 & Kent's Cavern & $6 / 3536$ & Hyena & HP & 4828 & 17,390 & 140 & 11.48 & $0.5-1$ & 10.50 \\
\hline P4100 & Kent's Cavern & $\mathrm{KC} 25$ & Breccia & $\mathrm{HCl}$ & 4272 & 5360 & 80 & 51.31 & 50 & \\
\hline P6060 & & RP4 & Shark & $\mathrm{HCl}-\mathrm{HP}$ & 4825 & 32,300 & 550 & 1.79 & 0 & 1.79 \\
\hline P5264 & Equus Cave & UCT 2979 & Quagga & HAc-HP & 4276 & 9830 & 120 & 29.41 & $25-28$ & 3.00 \\
\hline P5265 & Equus Cave & UCT 2985 & Megalotragus & HAc-HP & 4277 & 20,760 & 220 & 7.54 & $4.0-5.0$ & 3.00 \\
\hline
\end{tabular}

${ }^{*} \mathrm{HP}=$ phosphoric acid in first (HP1 or HP) or second (HP2) etch; $\mathrm{HAc}=$ acetic acid pre-etch; $\mathrm{HCl}=1 \mathrm{~N} \mathrm{HCl}$ and pre-etch; $\mathrm{HP}$ alone $=$ no pre-etch; Colla $=$ extracted collagen

$\nmid$ Percentage of carbon calculated for the expected date

\section{Discussion}

All the enamel dates are, as expected, somewhat too young. If only the main pretreatment method, treatment with acetic acid, is considered, the equivalent modern contamination level is fairly consistent at $6.5 \pm 2.8 \%$ (for $n=9$ ). This might be fortuitous, and further work might find less consistency, but given the different burial environments and laboratory procedures involved, we are inclined to interpret the results as showing that tooth enamel contains a moderately consistent fraction of comparatively recently exchanged or adsorbed carbonate that is resistant to removal by acetic acid. Much the same residual fraction seems to apply to the $200 \mathrm{ka}$ sample, the $20-40 \mathrm{ka}$ samples and the $11 \mathrm{ka}$ sample, implying that the incorporation of younger ${ }^{14} \mathrm{C}$ is recent (in comparison to the length of time of burial). That is to say, a relatively small amount of "modern" carbon is more likely as contaminant than a larger amount of older carbon. This would be consistent with the general results from stable isotope analysis, where incorporation of $<10 \%$ environmental carbon would not be easily detected.

The results show no effect ascribable to the time for which the samples have been exposed to the atmosphere away from their burial context. (Kent's Cavern samples have been stored in a museum for $>70 \mathrm{yr}$, Stanton Harcourt samples for $3 \mathrm{yr}$.) The results from $\mathrm{HCl}$ treatment are somewhat puzzling. $\mathrm{HCl}$ was used as an alternative to $\mathrm{HAc}$ because it appeared to cause less exchange in the oxygen isotopes of enamel carbonate. The initial result with Kent's Cavern (OxA-4273) was encouraging. However, all subsequent results on other material show the $\mathrm{HCl}$ treatment to be less successful than $\mathrm{HAc}$ in removing exogenous carbon. Presumably, the dissolution of hydroxyapatite by $\mathrm{HCl}$ is less discriminating. It is also worth pointing out that, although acetic acid treatment has clearly improved the date (where comparison is made with untreated material), the improvement is only 
about a factor of two ( $c a .1$ half-life). That is, the enamel does not seem to have incorporated particularly large amounts of "modern" carbon in the first place. One picture of this is that the carbonate remaining after acetic acid treatment contains a small proportion that remains in comparatively rapid equilibration with exogenous bicarbonate.

\section{The Prospect for the Accurate ${ }^{14} \mathrm{C}$ Dating of Enamel Carbonate}

The results reported here indicate an ambivalent prospect. On the one hand, the contamination has been reduced to a low and fairly consistent level; on the other hand, the very consistency obtained argues that it will be difficult to develop significantly improved methods to remove additional exogenous carbonate. If the present consistency (i.e., standard deviation in residual "modern" carbon) were taken as a random dating error, then an age limit of $c a$. $24 \mathrm{ka}$ BP would apply. This would have some, if limited, value. However, enamel is a valuable archaeological resource and is only abundant in megafaunal remains. For example, human enamel would be available for dating only in crucial cases, where reliability of dating is essential. Further improvements in removal of exogenous carbonate are likely to depend on improvements in understanding the processes of diagenesis alteration of enamel-research that is proceeding on a fairly broad front (e.g., in ESR dating (Rink and Schwarcz 1995), as well as in the recovery of dietary signals).

\section{Other Studies}

In terms of the contribution to other studies, these results tend to support the reliability of stable isotope determinations that use similar pretreatment methods. Although they do not distinguish decisively between the incorporation of major quantities of "older" carbon or minor quantities of "younger" carbon, they do suggest the latter to be more likely, and to be at a level that would not seriously compromise the $\delta^{13} \mathrm{C}$ measurements. They also suggest that, by the same argument, the extent of post-depositional structural alteration is small, so the accumulated ESR signal is not thereby greatly altered. Thus, this tends to support the reliability of the ESR methodology and suggests a possible test for ESR samples.

\section{ACKNOWLEDGMENTS}

We should like to record our thanks to the members of the Oxford Radiocarbon Accelerator Unit for the ${ }^{14} \mathrm{C}$ measurements. The Unit is currently partially supported by a research grant originating from NERC. We also thank the excavators and curators who allowed material in their care to be analyzed.

\section{REFERENCES}

Bocherens, H., Fogel, M. L., Tuross, N. and Zeder, M. 1995 Trophic structure and climatic information from isotopic signatures in Pleistocene cave fauna from Southern England. Journal of Archaeological Science 22(2): 327-340.

Brown, W. E. and Chow, L. C. 1976 Chemical properties of bone minerals. Annual Review of Materials Science 6: 213-250.

Haas, H. and Banewicz, J. 1980 Radiocarbon dating of bone apatite using thermal release of $\mathrm{CO}_{2}$. In Stuiver, M. and Kra, R. S., eds., Proceedings of the 10th International ${ }^{14} \mathrm{C}$ Conference. Radiocarbon 22(2): 537544.

Hassan, A. A., Termine, J. D. and Haynes, V. C., Jr. 1977 Mineralogical studies on bone apatite and their impli- cations for radiocarbon dating. Radiocarbon 19(3): 364-374.

Haynes, V. 1968 Radiocarbon: Analysis of inorganic carbon of fossil bone and enamel. Science 161: 687-688.

Koch, P. L., Tuross, N. and Fogel, M. L. 1995 Isotopic preservation of calcified tissue during early diagenesis. Geochimica Cosmochimica Acta, in press.

Kreuger, H. W. 1991 Exchange of carbon with biological apatite. Journal of Archaeological Science 18: 355361.

Lee-Thorp, J. A. (ms.) 1989 Stable Carbon Isotopes in Deep Time. Ph.D. dissertation, University of Cape Town, South Africa.

Lee-Thorp, J. A. and van der Merwe, N. J. 1991 Aspects of the chemistry of modern and fossil biological apa- 
tites. Journal of Archaeological Science 18: 343-354. Legeros, R. Z., Legeros, J. P., Trautz, O. and Klein, E. 1969 Two types of carbonate substitution in apatite structure. Experientia 24: 5-7.

Rey, C., Renugo, G., Palakrishnan, V., Shimuzu, M., Collins, B. and Glimcher, M. J. 1991 A resolution-enhanced fourier transform infra red study of the environment of the $\mathrm{CO}_{3}^{2-}$ ion in the mineral phase of enamel during its formation and maturation. Calcified Tissue International 49: 259-268.

Rink, W. J. and Schwarcz, H. P. 1995 Tests for diagenesis in tooth enamel: ESR dating signals and carbonate contents. Journal of Archaeological Science 22(2): 301-312.

Saliège, J.-F., Person, A. and Paris, F. 1995 Preservation of the ${ }^{13} \mathrm{C} /{ }^{12} \mathrm{C}$ original ratio and ${ }^{14} \mathrm{C}$ dating of the mineral fraction of human bones from Saharan tombs, Ni- ger. Journal of Archaeological Science 22(2): 301302.

Schoeninger, M. J. and DeNiro, M. J. 1983 Reply to: "Carbon isotope ratios of bone apatite and animal diet reconstruction". Nature 301: 177-178.

Stafford, T. W., Hare, P. E., Currie, L., Jull, A. J. T. and Donahue, D. J. 1991 Accelerator radiocarbon dating at the molecular level. Journal of Archaeological Science 18: 35-72.

Sullivan, C. Y. and Krueger, H. W. 1981 Carbon isotope analysis of separate chemical phases in modern and fossil bone. Nature 292: 333-335.

Sullivan, C. H. and Krueger, H. W. 1983 Carbon isotope ratios of bone apatite and animal diet reconstruction. Nature 301: 177.

Tamers, M. A. and Pearson, F. J. 1965 Validity of radiocarbon dates on bone. Nature 208: 1053-1055. 